\title{
Towards Universal Health Coverage: Exploring the Determinants of Household Enrolment into National Health Insurance in the Kassena Nankana District, Ghana
}

\author{
Kennedy A. Alatinga \\ Department of Community Development \\ Faculty of Planning and Land Management \\ University for Development Studies, Wa Campus, Ghana \\ Email: kalatinga@gmail.com \\ and \\ John J. Williams \\ School of Government \\ University of the Western Cape \\ South Africa \\ DOI//http://dx.doi.org/10.4314/gjdsv12i1\&2.6
}

\begin{abstract}
This study investigates the determinants of household participation in National Health Insurance Scheme (NHIS) in the Kassena-Nankana District in Ghana. In order to achieve this purpose, a cross-sectional survey was used to collect data from 417 randomly selected household heads. The results established that the NHIS is making incremental progress towards achieving universal health coverage because majority (67\%) of the sampled population was enrolled in the NHIS. However, further analysis of the data highlighted both the challenge of achieving equity of participation in health insurance and the yawning financial barriers to accessing health care for poor households and those employed in the informal sector. For example, majority (77\%) of uninsured households indicated that they were not enrolled in the NHIS because they could not afford the cost of insurance premiums. The research findings showed that income, socio-economic status (SES), formal employment, educational status, and gender amongst others, significantly determine household enrolment in health insurance. In order to increase the enrolment of the poor in the NHIS, and of achieving universal health coverage, the authors recommend that the government considers using payroll deductions to finance the health care needs of all formal sector employees while financing the health care of the rest of the population using tax revenues.
\end{abstract}


It is also recommeded that the NHIS considers making the payment of insurance premium flexible, such as allowing housholds to pay in installments or in kind.

Keywords: Universal Health Coverage, Determinants, Househol Enrolment, National Health Insurance, Premium, Kassena-Nankana District, Ghana

\section{INTRODUCTION}

Globally, universal health coverage (UHC) has been recognized as a key strategy that may reduce inequities in access to health care and promote good health, which is quintessential for human capital formation and socio-economic development (Evans, Marten, and Etienne, 2012; Gyimah-Brempong and Wilson, 2004). UHC requires that all residents in a country have adequate access to health care they need without suffering financial hardships irrespective of their socio-economic status (SES) or social influence(Carrin and James, 2004; World Health Organization (WHO, 2013). Similarly, the International Labour Organization (ILO) argues that universality of health coverage must involve equal access to needed health care for all people irrespective of where they live and work, in the formal or informal economy, SES, sex, and age (International Labour Organization, 2014). Consequently, in 2005, the World Health Assembly called on all health systems to move towards UHC by "ensuring that health-financing systems include a method for prepayment of financial contributions for health care, with a view to sharing risk among the population and avoiding catastrophic health-care expenditure and impoverishment of individuals as a result of seeking care" (World Health Organization [WHO], 2005).

To this effect, it is argued that health insurance has the potential to bridge the equity gap in access to health and attaining UHC (Akazili, Gyapong, \& McIntyre, 2011).The primacy of health insurance as a key financing policy for increasing access to health care, reducing health inequalities, and extending UHC especially to the poor in developing countries has been established (Nguyen, Rajkotia, \& Wang, 2011; World Health Organization (WHO), 2013). For example, Alatinga and Williams (2014) argue that health insurance improves the poor's access to health care and protects them against the costs of illness.

With a view to reducing disparities in access to health care, in 2004 Ghana implemented its flagship social protection policy - the National Health Insurance Scheme (NHIS) with the aim of achieving UHC (Government of Ghana, 2012). The prime objective of the NHIS is to achieve UHC by increasing the access of all residents in Ghana to affordable and quality health care (Government of Ghana, 2012). As a prepayment mechanism, the NHIS does not entail deductibles and co-payments - which makes it an important policy intstrument for achieving UHC. The NHIS replaced the hitherto user-fee policy, popularly known as 'cash and carry system', which greatly limited individuals and households access to health care especially for the poor because health-seekers had to pay cash at the point of demanding health care (Nyonator \& Kutzin, 1999). Even though exemptions were granted to the very poor to cushion them from the financial burden imposed by the cash and carry system, 
these exemptions could not be effectively implemented due to unclear guidelines for determining and interpreting who was poor enough to be exempted (Britwum, Jonah, \& Tay, 2001).

The NHIS was designed to cover both formal and informal sector workers simultaneously through a combination of insurance premiums and taxes (Abiiro \& McIntyre, 2013; Government of Ghana, 2012). In principle, enrolment in the NHIS is mandatory. But the management of the NHIS is unable to enforce this mandtory principle because informal sector employees have to make an annual premium payment before they are enrolled (Abiiro \& McIntyre, 2013). Further, the NHIS insurance premiums are supposed to be structured based on individual or household's ability to pay. However, due to the large informal sector and corresponding difficulties in assessing income and living standards of informal sector households, flat rate insurance premiums are charged by the NHIS at the district schemes (Abiiro \& McIntyre, 2013; Jehu-Appiah, Aryeetey, Spaan, Agyepong, \& Baltussen, 2010). To relieve the poor and vulnerable of the burden of the flat rate insurance premiums, the indigent are exempted from paying insurance premiums by providing them with government subsidies. To address universal health coverage speedily, and in order to reduce child and maternal mortality, children under 18 years of age and pregnant women are further exempted. Also exempted are: the aged (7o years and above) and pensioners of the Social Security and National Insurance Trust [SSNIT] (Government of Ghana, 2012). Alatinga and Williams (2014) report that the NHIS is publicly financed from three main sources: Firstly, $70 \%$ of the NHIS funds come from a $2.5 \%$ value-added tax (VAT). Secondly, approximately $25 \%$ of the funds come from a $2.5 \%$ contribution from the Social Security and National Insurance Trust (SSNIT) for formal sector employees except university lecturers and all other formal sector workers that are not under SSNIT. This implies that SSNIT employees are also exempted from paying direct insurance premiums to the district insurance schemes in order to be enrolled. The third source of funding for the NHIS is an annual insurance premium which is paid by informal sector workers to the scheme, and it constitutes approximately $5 \%$ of funding to the scheme (Aryeetey, JehuAppiah, Spaan, Agyepong, \& Baltussen, 2012).

The rest of the paper is organised as follows: section two presents the research problem while section three details the conceptual framework. Section four then exemplifies the research methodoloy while the research results are presented in section five. Section six discusses the research results, and section seven concludes the paper.

\section{RESEARCH PROBLEM}

There has been huge research interest in the NHIS since its implementation a decade ago. With specific reference to the potential of the NHIS in achieving UHC, Jehu-Appiah, Aryeetey, Spaan, Agyepong, and Baltussen (2010) have examined the efficiency, equity and feasibility of alternative strategies to identify the poor in order to exempt them from paying premiums. Additionally, Abiiro and McIntyre (2012) have explored stakeholders' 
views on extending insurance coverage to informal sector workers with the aim of achieving UHC. Similarly, Amporfu (2013) has detailed the equity of the NHIS premium and its implications for achieving UHC. Amporfu (2013) argues that the insurance premium is an important determinant for achieving UHC because the poor are less likely to enroll in the NHIS than the rich. However, none of the aforementioned studies has systematically examined the determinants of household enrolment in the NHIS. Examining the determinants of household enrolment in the NHIS is of critical policy importance because individual and household enrolment in the NHIS remains quite low after 10 years of implementation (National Health Insurance Authority [NHIA], 2011). For example, available evidence suggests that the NHIS covers about $33 \%$ of the Ghanaian populationof which, $4 \%$ only of the poor are covered. Additionally, available data suggests that $64 \%$ of the richest population are enrolled (insured) in the NHIS whereas $26 \%$ of the poorest people only are enrolled in the NHIS (Oxfam International, 2011). Similarly, Akazili, Garshong, Aikins, Gyapong, and McIntyre, (2012) argue that the distribution of total benefits from using health care in Ghana is pro-rich-the richest quintile gained almost double (24\%) the benefits gained by the poorest (13\%). The authors further suggest that the two richest quintiles accounted for almost half of total health care benefits, whilst the two poorest quintiles gained less than $30 \%$ of total public and private health care benefits.

Importantly, very little is known about the equity of enrolment of households in the NHIS categorised by income, gender, educational status, age, marital status and ethnicity, amongst others. Jütting (2003) argues that these characteristics are important to evaluate whether or not health insurance addresses the problem of social exclusion from access to health care. Yet, there is currently a dearth of systematic and empirical evidence using household surveys to estimate the determinants of enrolment in the NHIS in Ghana. This study contributes to bridging this gap in knowledge by examining the determinants of household participation in the NHIS. From a policy pespective, understanding the determinants of household enrolment in the NHIS could inform policy-makers on how to design effective strategies to increase household enrolment in health insurance in order to reduce the financial burden of health care, and improve health.

\section{CONCEPTUALISING THE DETERMINANTS OF ENROLMENT IN HEALTH INSURANCE}

Health Insurance (HI) is a scheme for mobilising and utilising resources through a risksharing mechanism to finance the health care needs of members in a manner that reflects the values of solidarity and shared responsibility for health care (Doetinchem, Carrin, \& Evans, 2010; Wagstaff, 2010). Health insurance systems have been traditionally financed entirely by payroll deductions (social health insurance) especially in developed countries, such as Germany and Japan-but HI systems have evolved to cover informal sector employees who have no regular sources of income (Doetinchem et al., 2010). Most informal sector employees often pay flat rate insurance premiums due to the fact that their incomes are difficult to identify (Doetinchem et al., 2010). Generally, but not always, 
contributions have ensured that the rich contribute more than the poor but contributions do not typically vary with health status (Doetinchem et al., 2010). Additionally, governments in developing countries have also extended HI coverage to the poor by subsidising their contributions from government tax revenues. Thailand is a success story where, the health system uses payroll contributions for only $12 \%$ of its population and finances the rest of the population's health using tax revenues, which is benefiting mostly the poor (Oxfam International, 2013).

Given the large informal sector and corresponding difficulties in assessing income and living standards of informal sector households in developing countries, many households risk being socially excluded from social health protection. Ekman (2004) argues that household enrolment in $\mathrm{HI}$ is not automatic-even small premiums may exclude most little well-off households from participating in health insurance. Jütting (2005) supports this claim, arguing that high-income households are more likely to participate in insurance than low-income households. In a study in Senegal, Jütting (2003) found that the poorer strata of the population is less represented in health insurance as compared to the average and high-come households. Similarly, Richardson, Roberts, Sava, Menon and McKee (2012) found that the poor were more likely to lack insurance coverage; those on very low incomes were more than twice as likely to be uninsured as compared to those on highest incomes in Moldova. Jütting's (2003) study further established that age and gender appear to influence participation in insurance because the probability of women and older people being insured is higher than for male and younger persons in the household.

Literature reviewed suggests that education and formal sector employment are positively associated with household participation in health insurance. Kimani, Ettarh, Kyobutungi, Mberu, and Muindi (2012)where a total of about 60,00o individuals living in approximately 23,000 households are under surveillance. Descriptive statistics and multivariate logistic regression analysis were used to describe the characteristics of the sample and to identify factors associated with participation in the NHIF program. $\mid n \backslash$ nResults $\backslash$ nOnly $10 \%$ of the respondents were participating in the NHIF program, while less than $1 \%$ (o.8\% reported that more women employed in the formal sector are insured than their counterparts working in the informal sector in Kenya. With respect to education, Kimani et al. (2012) suggest that having health insurance coverage is associated with educational status. The authors claim that more educated women were more likely to have health insurance relative to women with no formal education. Last but not the least, Kirigia, Sambo, Nganda, Mwabu, Chatora and Mwase (2005) also found that married couples were more likely to have health insurance as compared to single or divorced persons in South Africa.The above mentioned scholarship further underscores the importance of exploring the determinants of household enrolment in the NHIS with a view to achieving UHC in the Ghanaian context. 


\section{METHODOLOGY}

This study was conducted in the Kassena-Nankana District (KND) in Northern Ghana between February 2013 and July 2013. The list of all the 13 Districts in the Upper East Region constituted the sample frame, out of which the KND was randomly selected for this study. A cross-sectional survey design was used to collect data from household heads or adults in the household who are responsible for the household welfare and make financial decisions about whether or not the household enrolls in health insurance. A household was defined as a person or a group of persons, related or unrelated, who live together in the same house or compound, share the same housekeeping arrangements, and eat together as a unit (Ghana Statistical Service, 2008). A sampling frame containing all the households in the KND was obtained from the Navrongo Demographic Surveillance System (NDSS)3. Simple random sampling was then used to select 417 households across the KND to participate in the study. A structured questionnaire was used to collect the required information from the respondents. The questionnaire collected data on the socio-demographics of respondents. The questionnaire further asked respondents to indicate their health insurance status and the reasons that motivated them to either enrol or not enrol in the national health insurance scheme. Household data was captured into a database using Epidata and exported to STATA version 12.0 for analysis. Descriptive statistics, cross tabulations and logistic regression were used to analyse the data. A poverty index was generated using principal component analysis (PCA) to determine the SES of households based on their possessions and assets. PCA is a statistical procedure used to determine weights for a linear index of a set of variables (Filmer and Pritchett, 2001).The assets and possessions that were used for the PCA included bicycles, motor bikes, vehicles, beds, radios, mobile telephones, cooking fuel, cattle, sheep, goats, pigs and donkeys and, as regards the dwellings, number of rooms, type of material used for walls, roofing material, toilet material and sources of drinking water. Ownership of these assets and possessions is perceived as an important proxy of household economic status because a lot of value is attached to assets and posessions. Thus, households with all these possessions and assets are perceived as the "better off" by residents in the study communities as compared to households that had either very few or none of these possessions.

\section{RESEARCH RESULTS}

\section{Socio-demographic characteristics of respondents}

This study found a high health insurance coverage rate among the sampled population- $67 \%$ households were enrolled whereas $33 \%$ of households were not enrolled in the NHIS. Of the $67 \%$ enrolled households however, only $3 \%$ of them were indigent households. The study findings further showed that males and females constituted $72 \%$

3 NDSS is a Unit of the Navrongo Health Research Centre that collects and updates demographic data in the KND 
and $28 \%$ respectively of the respondents in the study population. The mean age in the sample was 51 years. The mean household size was 5 while the minimum and maximum household sizes were 1 and 13 respectively. In addition, $74 \%$ of the study population was married while $19 \%$ had been widowed. In terms of education, the majority $(55 \%)$ of the study population had never been to school while $8 \%$ only had reached the tertiary level of education. With respect to employment, $60 \%$ were farmers while $7 \%$ were unemployed. Table 1 summarises the characteristics of the respondents.

Table 1: Socio-demographics characteristics of respondents

\begin{tabular}{|c|c|c|c|}
\hline Sex of respondents & Frequency (\%) & Insured (\%) & Uninsured (\%) \\
\hline Male & $301(72.0)$ & $199(71.3)$ & $102(74.0)$ \\
\hline Female & $116(28.0)$ & $80(28.7)$ & $36(26.0)$ \\
\hline \multicolumn{4}{|l|}{ Marital status of respondents } \\
\hline Married & $310(74.0)$ & $210(75 \cdot 3)$ & $99(71.7)$ \\
\hline Never married & $11(3.0)$ & $9(3.2)$ & $2(1.5)$ \\
\hline Divorced & $19(4.0)$ & $12(4.3)$ & $7(5.1)$ \\
\hline Widow & $78(19)$ & $48(17.2)$ & $30(21.7)$ \\
\hline \multicolumn{4}{|l|}{ Ethnicity of respondents } \\
\hline Kasem & $251(60.2)$ & $172(61.6)$ & $79(57.3)$ \\
\hline Nankam & $143(34 \cdot 3)$ & $87(31.2)$ & $46(40.5)$ \\
\hline Buli & $12(2.9)$ & $10(3.6)$ & $2(1.5)$ \\
\hline Other & $11(2.6)$ & $10(3.6)$ & $1(0.7)$ \\
\hline \multicolumn{4}{|c|}{ Educational level of respondents } \\
\hline Never been to school & $231(55.4)$ & $130(46.6)$ & $101(73.1)$ \\
\hline Primary & $70(16.8)$ & $47(16.8)$ & $23(16.7)$ \\
\hline Junior high school & $45(10.8)$ & $37(13.3)$ & $8(5.8)$ \\
\hline Senior high school & $39(9.4)$ & $33(11.8)$ & $6(4.4)$ \\
\hline Tertiary & $32(7.6)$ & $32(11.5)$ & $\mathrm{o}(0.0)$ \\
\hline \multicolumn{4}{|l|}{ Occupation of respondents } \\
\hline Farmer & $250(59.9)$ & $145(52.7)$ & $101(73.2)$ \\
\hline Trader & $75(18.0)$ & $53(19.3)$ & $22(15.9)$ \\
\hline Employed in the formal sector & $53(12.8)$ & $50(18.2)$ & $3(2.2)$ \\
\hline Retired/Pensioner & $6(1.4)$ & $5(1.8)$ & $1(0.7)$ \\
\hline Student & $4(0.9)$ & $4(1.4)$ & $\mathrm{o}(0.0)$ \\
\hline Unemployed & $29(7.0)$ & $18(6.6)$ & $11(8.0)$ \\
\hline
\end{tabular}

Source: Field survey, April 2013

94 GJDS, Vol. 12, No. 1 \& 2, 2015 
A cross-tabulation of the SES of households against their insurance status showed that $68 \%$ of the households that were enrolled were not poor while $32 \%$ of the households with the same SES were not enrolled. On the other hand, about $65 \%$ of poor household were not enrolled while $35 \%$ of poor households were enrolled. The reasons for household enrolment or non-enrolment are detailed below.

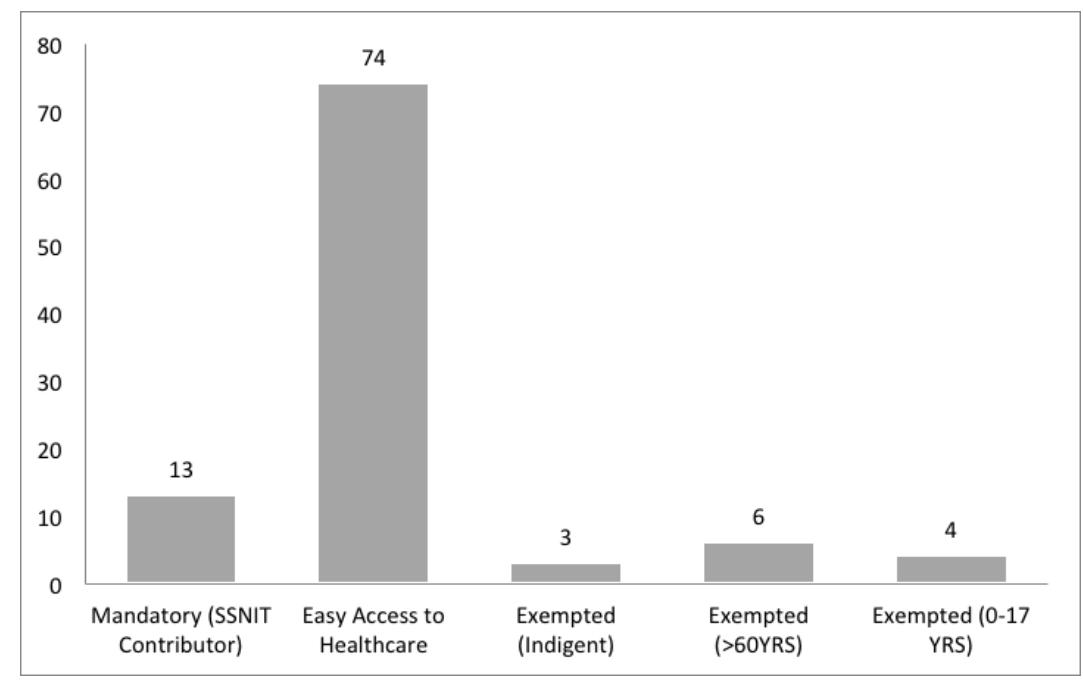

Figure 1: Reasons for enrolling in the NHIS

As illustrated in figure 1, Seventy-four per cent, almost 3 out of every 4 of the respondents indicated that they had enrolled in the NHIS because of easy access to health care as the NHIS protected them against the financial cost of illness. In addition, $13 \%$ of the respondents were enrolled in the NHIS because they were formal employees contributing to SSNIT. The exempted categories of people also constituted another $13 \%$ of the sampled population. On the other hand, respondents that were not enrolled in the NHIS listed the following reasons for their choice as shown in figure 2 . 


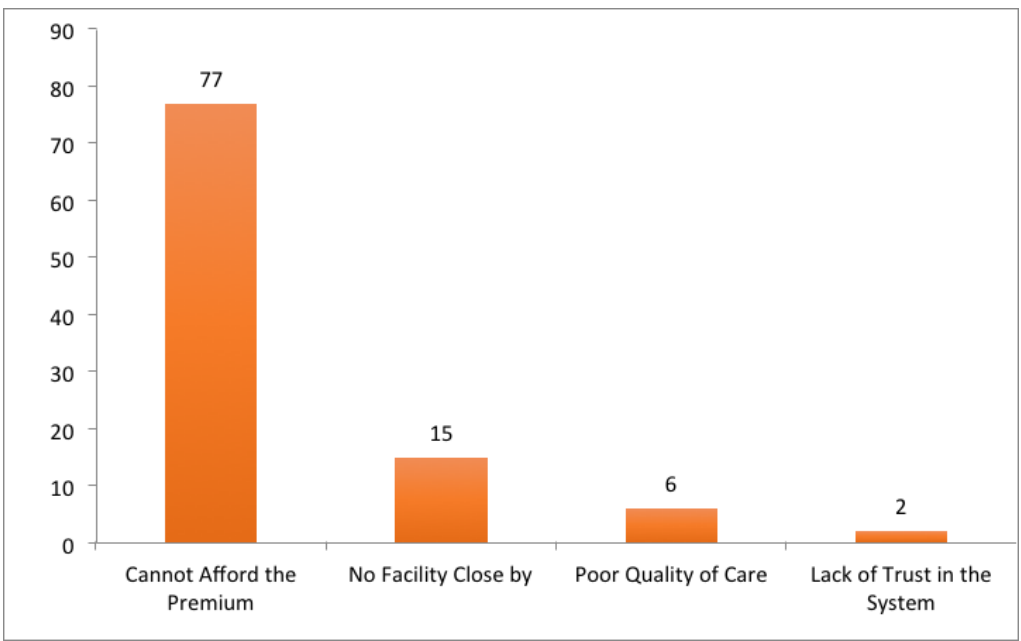

Figure 2: Reasons for not enrolling in the NHIS

As illustrated in figure 2, the research results showed that unaffordability of insurance premium is the cardinal reason constraining households from enrolling in the NHIS. In fact, of the unenrolled households, $77 \%$ of households indicated that they were not enrolled in the NHIS because they could not afford the cost of insurance premiums. Proximity to the nearest health facility is another major reason households did not enroll in the NHIS. Fifteen per cent of household were not enrolled in the NHIS because there are no health facilities close to them. This suggests that this category of people walk for more than 30 minutes to reach the nearest health facility because access to health to health care is defined as people who walk 30 minutes or less to reach the nearest health facility (Canagarajah and Ye, 2001). Similarly, $6 \%$ and $2 \%$ of households failed to enroll due to perceived poor quality of health care and lack of trust in the insurance scheme respectively. Quality health care in this specific context related to the timely manner in which patients are attended to at the district hospital, provider attitude towards patients and the availability of essential drugs (Alatinga \& Williams, 2014).

\section{Estimating the Determinants of Household Enrolment in the NHIS}

From the preceding more descriptive analysis, a multivariate logistic regression model was used to estimate the determinants for household enrolment in the NHIS as presented in table 2. 
Table 2: Determinants of household enrolment in the NHIS

\begin{tabular}{|c|c|c|c|c|}
\hline Predictors & Response & Odds Ratio & $95 \%$ CI & P-value \\
\hline \multirow[t]{2}{*}{ Household income } & $\$ 32-46$ & 1 & & \\
\hline & $\$ 4-27$ & 0.47 & $0.28,0.75$ & 0.002 \\
\hline \multirow[t]{2}{*}{ SES } & Poor & 1 & & \\
\hline & Not Poor & 1.64 & $1.01,2.66$ & 0.045 \\
\hline \multirow[t]{3}{*}{ Age } & $<40$ years & 1 & & \\
\hline & 40-59 years & 1.18 & $0.66,2.11$ & 0.570 \\
\hline & 60 years + & 2.04 & $1.04,3.99$ & 0.038 \\
\hline \multirow[t]{3}{*}{$\begin{array}{l}\text { Education of household } \\
\text { head }\end{array}$} & Never & 1 & & \\
\hline & Basic & 2.31 & $1.32,4.03$ & 0.003 \\
\hline & Post-secondary & 4.28 & $1.43,12.8$ & 0.009 \\
\hline \multirow[t]{2}{*}{ Gender of household head } & Female & 1 & & \\
\hline & Male & 2.53 & $1.24,5.14$ & 0.011 \\
\hline \multirow[t]{3}{*}{$\begin{array}{l}\text { Occupation of household } \\
\text { head }\end{array}$} & Informal & 1 & & \\
\hline & Formal & 3.70 & $0.93,14.7$ & 0.033 \\
\hline & Retired & 1.70 & $0.61,15.9$ & 0.690 \\
\hline \multirow[t]{3}{*}{ Household size } & Small & 1 & & \\
\hline & Medium & 1.17 & $0.63,2.17$ & 0.617 \\
\hline & Large & 0.91 & $0.44,1.87$ & 0.804 \\
\hline \multirow[t]{4}{*}{$\begin{array}{l}\text { Marital status of } \\
\text { household head }\end{array}$} & Married & 1 & & \\
\hline & Divorced & 0.99 & $0.32,3.05$ & 0.992 \\
\hline & Widow & 0.5 & $0.20,1.08$ & 0.003 \\
\hline & Other & 1.02 & $0.22,4.67$ & 0.980 \\
\hline \multirow[t]{4}{*}{ Ethnicity } & Kasem & 1 & & \\
\hline & Nankam & 0.84 & $0.51,1.37$ & 0.487 \\
\hline & Builsa & 4.72 & $0.93,24.1$ & 0.062 \\
\hline & Other & 2.91 & $0.33,26.0$ & 0.339 \\
\hline
\end{tabular}

Source: Field work, April 2013 
The results of the logistic regression in table 2 above show that the variables-income, SES, age, education, gender, formal employment, and marital status significantly influence household enrolment in the NHIS at 95\% significance level. Households that earn a monthly income of between $\$ 4$ and $\$ 27$ are 0.47 times less likely to enrol in the NHIS. In other words, the chances or probability of these households actually enrolling in the NHIS is 0.47 times less as compared to households that earn between $\$ 32 a n d \$ 46$. The results are statistically significant with a p-value of $(\mathrm{p}=0.002)$. Similarly, widowed households are 0.5 times less likely to enrol in the NHIS as compared to married households with a significant $\mathrm{p}$-value $(\mathrm{p}=\mathrm{0.003})$. In addition, non-poor households were nearly twice as likely to enroll in health insurance as compared to poor housholds, with a significant p-value of $(\mathrm{p}=0.045)$. Table 2 shows, male-headed households were almost three times more likely to enrol in the NHIS as compared to the female-headed households with a significant $\mathrm{p}$-value of $(\mathrm{p}=\mathrm{0.011})$. Similarly, household heads that have attained post-secondary levels of education are nearly 5 times more likely to participate in the NHIS as compared to those who have never attended school. The results are also statistically significant with a $\mathrm{p}$-value of $(\mathrm{p}=0.009)$. Age and formal employment are equally important determinants of enrolment in the NHIS. As illustrated in table 2 people aged 60 years and above are twice as likely to enrol in the NHIS as compared to people who are less than 40 years, with a p-value of $(p=0.038)$ and household heads employed in the formal sector are nearly 4 times more likely to participate in health insurance as compared to those employed in the informal sector.

\section{Discussion of Findings}

This paper explored the determinants of household enrollment in the NHIS in Ghana. The findings showed the nascent NHIS is making incremental progress towards achieving universal health coverage in Ghana. Over half $(67 \%)$ of the sampled population was enrolled in the NHIS compared to $33 \%$ that was not enrolled. In fact, seventy-four per cent of insured households indicated that financial protection against the cost of illness is the major reason for which they are enrolled in te NHIS. This finding is logical and is largely consistent with a relatively large body of literature documenting the NHIS and access to health care in Ghana. For example, Jehu-Appiah, Aryeetey, Agyepong, Spaan, and Baltussen (2012) found out that $76 \%$ of household cited financial protection against the cost of illness as the main reason for enrolling in the NHIS. Studies by Aryeetey et al. (2013) corroborate this claim, suggesting that the NHIS generally improves access to health care. This high enrollment rate of households in the NHIS is commendable, and reinforces the potential of health insurance as a tool for bridging the gap in access to health care and attaining UHC in developing countries provided there is policy commitment and political will to formulate and implement health care policies and services pro-actively (Akazili et al., 2011).

In fact, studies have indicated that through health insurance and other mechanisms such as taxes, Thailand has successfully extended UHC to its poor and disadvantaged 
population due largely to both strong political commitment and to active civil society engagement (Oxfam International, 2013). However, about $77 \%$ of households failed to enrol in the NHIS because they could not afford the flat insurance premiums, suggesting that financial constrains are still preventing these households from enrolling in the NHIS, thus denying them access to affordable and quality health care. These results are consistent with earlier studies in other developing countries documenting the major barrier to accessing health care. For example, Dong, De Allegri, Gnawali, Souares, and Sauerborn (2009) found out that in Burkina Faso, affordability of premiums is cited as the major road block for low enrolment in health insurance.

In Vietnam, a study of a sample of 3500 households reported that health insurance uptake was low due to the inability of households to pay insurance premiums (Acharya et al., 2012). In fact, this claim has been proven by the regression analysis as demonstrated in table 2 because both income and SES significantly predicted household enrolment in health insurance. These findings confirm earlier ones that suggested that income and SES are key predictors of enrollment in health insurance. For example, in Moldova, Richardson et al. (2012) found that households with very low incomes were more than twice as likely to be uninsured as compared with highest incomes households. Similar studies in Cameroon, Kenyan and Senegal highlight income as an important determinant of enrolment in health insurance (Bonan, LeMay-Boucher, \& Tenikue, 2014; Donfouet, Makaudze, Mahieu, \& Malin, 2011; Kimani et al., 2012). Further analysis of the regression results showed that both the educational level and the type of occupation of household heads were key determinants of enrolment in the NHIS. Households with post-secondary level of education were found to be almost five times more likely to enroll in health insurance as compared to those that had no education at all. Also, households employed in the formal sector were nearly 4 times more likely to participate in health insurance as compared to households employed in the informal sector. These findings are logical in the sense that education leverages knowledge to households in the form of acquired skills and innovative ideas-thus, heads of households with tertiary levels of education are more employable in better paid jobs as compared to the heads of households with no such education. In fact, Sen (1999) argues that both better education and better health help in earning higher incomes, while Adams (2011) is unequivocal, pointing out that post-secondary education improves the chances of both households and individuals of finding employment and earning higher incomes. In South Africa, Kirigia et al. (2005) found out that households with at least a matriculation or secondary level of education were two times more likely to be in possession of a health insurance policy than those with a lower level of education. Again in Moldova, Richardson et al. (2012) specifically reported that self-employed agricultural sectors workers were over 27 times more likely to lack insurance cover as compared to those employed in the formal sector. The differences in health insurance coverage between the informal and formal sector employees have important policy implications for the NHIS as it aims to extend universal health coverage to the entire population - because the findings also mirror the experience of other low and middle countries seeking to extend health insurance to informal sector employees. 
For example, available literature indicates that it took about 30 years for South Korea to incrementally expand health insurance to informal sector employees (Richardson et al., 2012).

The findings of this study further showed that both gender and marital status significantly determined household enrolment in the NHIS as illustrated in Table 2. Male headed households were almost 3 times more likely to participate in health insurance as compared to their female counterparts. Similarly, households headed by widows were 0.5 times less likely to participate in insurance as compared to married household heads. The differences in enrolment in the NHIS between male and female headed household may be ascribed to the unequal gender relations of power at the household level. For example, Matsa (2011) argues that poverty in Africa is feminised because female-headed households lack access to, and control over resources, such as land, as compared to their male counterparts. In Kenya, Kimani et al. (2012)where a total of about 6o,ooo individuals living in approximately 23,000 households are under surveillance. Descriptive statistics and multivariate logistic regression analysis were used to describe the characteristics of the sample and to identify factors associated with participation in the NHIF program. $\backslash n \backslash$ nResults $\backslash$ nOnly $10 \%$ of the respondents were participating in the NHIF program, while less than $1 \%$ ( $0.8 \%$ found out that participation in the health insurance was significantly higher for men than for women. Also, Kirigia et al. (2005) found out that married couples were more likely to have health insurance as compared to divorced persons. Three reasons have been advanced by (Kirigia et al., 2005) for which married household may have a higher demand for health insurance - the need to protect their children, higher combined income and being more averse to the risk of catastrophic health expenditures than those who are single, separated or divorced.

It is important to state that even though the research findings of this study are largely consistent with the existing literature, the findings also raise equity issues. For example, the large discrepancy in enrolment in the NHIS between male and female-headed households speaks to issues of inequity. Thus, addressing these disparities in enrolment in the NHIS between these demographic groups of people may quicken the pace towards achieving universal health coverage. Finally, the research findings also established that age is an important determinant of enrolment in health insurance. These findings make sense because people aged 60 years and above are theoretically more vulnerable to illnesses and, thus, require medical care more often as compared to younger people in the household. For example, Jütting (2003) argues that as individuals advance in age, their inherited health stock depreciates at an increasing rate, manifesting the biological process of ageing; hence they tend to increase investments in health, including health insurance in an attempt to decrease the rate of depreciation. 


\section{CONCLUSION AND RECOMMENDATIONS}

This paper explored the determinants of household enrolment in the NHIS in Ghana. The findings showed NHIS is substantially achieving its objective of providing financial protection to the people, particularly the poor and vulnerable because $13 \%$ of these categories of people are found to be exempted from paying insurance premiums in the study area. It can thus be concluded that the NHIS is making incremental progress towards achieving universal health coverage. The results of the logistic regression above showed that income, SES, age, education, gender, formal employment, and marital status significantly determine household enrolment in the NHIS.

However, in order to achieve universal health coverage, concerted and decisive efforts are still needed as the costs of insurance premiums constitute the major challenge preventing households from enrolling in the NHIS. In addition, equity concerns have also been highlighted - the large discrepancy in enrolment in the NHIS between male and femaleheaded households raises issues of inequity which may impede the NHIS' progress towards universal health coverage.

It is recommended that the management of the NHIS considers making the payment of insurance premium flexible, such as allowing housholds to pay in installment or in kind. This strategy may help address the challenge of affordability of insurance premiums for the least better-off families. In order to address the equity concerns raised, the managemnt of the NHIS may also consider giving subsidies to female-headed households, particularly those who have children and are unemployed. Identifying unemployed widows and widowers with children would be easy to apply at the community level since it could be verified empirically. For example, the management of the NHIS at the District level could call upon community leaders such as chiefs and assembly members to help identify unemployed widows and widowers with children within their juridiction in order to exempt these categories of people from paying annual health insurance premiums. Exempting unemployed widows and widowers from paying annual health insurance premiums may increase their access to health care.

It is further recommended that the government considers using payroll deductions to finance the health care needs of all formal sector employees while financing the health care of the rest of the population using tax revenues. Addressing these issues promptly and decisively may quicken the move towards achieving universal health coverage in Ghana with lessons for other countries with similar health care challenges. 


\section{References}

Abiiro, G. A. and McIntyre, D. (2012). Achieving universal health care coverage: Current debates in Ghana on covering those outside the formal sector. BMC International Health and Human Rights, 12, pp. 25.

Abiiro, G. A. and McIntyre, D. (2013). Universal financial protection through National Health Insurance: a stakeholder analysis of the proposed one-time premium payment policy in Ghana. Health Policy and Planning, 28(3), pp. 263-278.

Acharya, A., Vellakkal, S., Taylor, F., Masset, E., Satija, A., Burke, M. and Ebrahim, S. (2012). The impact of health insurance schemes for the informal sector in Low - and middle-income Countries: a systematic review. The World Bank Research Observer, lksoog.

Adams, A. V. (2011). The role of skills development in overcoming social disadvantage. Paris, France: UNESCO. Retrieved from http://www.unesco.org/new/fileadmin/ MULTIMEDIA/HQ/ED/pdf/gmr2012-ED-EFA-MRT-PI-04.pdf

Akazili, J., Garshong, B., Aikins, M., Gyapong, J. and McIntyre, D. (2012). Progressivity of health care financing and incidence of service benefits in Ghana. Health Policy and Planning, 27(suppl 1), pp.13-22.

Akazili, J., Gyapong, J., \& McIntyre, D. (2011). Who pays for health care in Ghana? International Journal for Equity in Health, 10 (1), 26.

Amporfu, E. (2013). Equity of the premium of the Ghanaian national health insurance scheme and the implications for achieving universal coverage. International Journal for Equity in Health, 12(1), pp. 4.

Aryeetey, G. C., Jehu-Appiah, C., Kotoh, A. M., Spaan, E., Arhinful, D. K., Baltussen, R., and Agyepong, I. A. (2013). Community concepts of poverty: an application to premium exemptions in Ghana's National Health Insurance Scheme. Globalization and Health, 9(1), pp.12.

Aryeetey, G. C., Jehu-Appiah, C., Spaan, E., Agyepong, I. and Baltussen, R. (2012). Costs, equity, efficiency and feasibility of identifying the poor in Ghana's National Health Insurance Scheme: empirical analysis of various strategies. Tropical Medicine and International Health, 17(1), pp. 43-51.

Bonan, J., LeMay-Boucher, P. and Tenikue, M. (2014). Households' willingness to pay for health microinsurance and its impact on actual take-up: results from a Field Experiment in Senegal. Journal of Development Studies, 50(10), pp. 1445-1462. 
Britwum, A., Jonah, K. and Tay, F. D. (2001). Structural adjustment participatory review initiative (Sapri) (Ghana Country Report). Accra-Ghana.

Canagarajah, S. and Ye, X. (2001). Public health and education spending in Ghana in 1992-98: issues of equity and efficiency (Policy Research Working Paper No. 2579). Washington, DC: The World Bank.

Carrin, G. and James, C. (2004). Reaching universal coverage via social health insurance: key design features in the transition period (Discussion paper No. 2). Geneva: World Health Organization. Retrieved from http://apps.who.int/iris/bitstream/10665/69018/1/ EIP_FER_DP_04.2.pdf

Doetinchem, O., Carrin, G. and Evans, D. (2010). Thinking of introducing social health insurance? Ten questions (World Health Report (2010) Background Paper No. 26). Geneva: World Health Organization.

Donfouet, H. P. P., Makaudze, E., Mahieu, P. A. and Malin, E. (2011). The determinants of the willingness-to-pay for community-based prepayment scheme in rural Cameroon. International Journal of Health Care Finance and Economics, 11(3), pp. 209-220.

Dong, H., De Allegri, M., Gnawali, D., Souares, A. and Sauerborn, R. (2009). Dropout analysis of community-based health insurance membership at Nouna, Burkina Faso. Health Policy, 92(2-3), pp. 174-179.

Ekman, B. (2004). Community-based health insurance in low-income countries: a systematic review of the evidence. Health Policy and Planning, 19(5), pp. 249-270.

Evans, D. B., Marten, R. and Etienne, C. (2012). Universal health coverage is a development issue. The Lancet, 380(9845), pp. 864-865.

Filmer, D., and Pritchett, L. H. (2001). Estimating wealth effects without expenditure data-or tears: an application to educational enrollments in states of India. Demography, 38(1), pp.115-132.

Ghana Statistical Service. (2008). Ghana demographic and health survey 2008. AccraGhana: Ghana Statistical Service. Retrieved from http://dhsprogram.com/pubs/ pdf/FR221/FR221\%5B13Aug2012\%5D.pdf

Government of Ghana. National Health Insurance (NHI) Act, (Act 852), Pub. L. No. Act 852 (2012).

Government of Ghana Accra-Ghana. National Health Insurance Act, 2012, Pub. L. No. Act 852 (2012). 
Gyimah-Brempong, K. and Wilson, M. (2004). Health human capital and economic growth in Sub-Saharan African and OECD countries. The Quarterly Review of Economics and Finance, 44(2), pp. 296-320.

International Labour Organization. (2014). World social protection report 2014/15: Building economic recovery, inclusive development and social justice. Geneva: International Labour Office. Retrieved from http://www.ilo.org/wcmsp5/groups/ public/-dgreports/-dcomm/documents/publication/wcms_245201.pdf

Jehu-Appiah, C., Aryeetey, G., Agyepong, I., Spaan, E. and Baltussen, R. (2012). Household perceptions and their implications for enrolment in the National Health Insurance Scheme in Ghana. Health Policy and Planning, 27(3), pp. 222-233.

Jehu-Appiah, C., Aryeetey, G., Spaan, E., Agyepong and Baltussen, R. (2010). Efficiency, equity and feasibility of strategies to identify the poor: an application to premium exemptions under National Health Insurance in Ghana. Health Policy (Amsterdam, Netherlands), 95(2-3), pp. 166-173.

Jütting, J. (2003). Health insurance for the poor? Determinants of participation in community-based health insurance schemes in rural Senegal (Working Paper No. 204). Paris, France: OECD Development Centre. Retrieved from http://www.oecd.org/ $\mathrm{dev} / 2492297 \cdot \mathrm{pdf}$

Jutting, J. (2005). Health insurance for the poor in developing Countries. Croft Road, Aldershot. Hampshire GU113HR, England: Ashgate Publishing Limited, Gower House.

Kimani, J. K., Ettarh, R., Kyobutungi, C., Mberu, B. and Muindi, K. (2012). Determinants for participation in a public health insurance program among residents of urban slums in Nairobi, Kenya: results from a cross-sectional survey. BMC Health Services Research, 12, pp. 66.

Kirigia, J. M., Sambo, L. G., Nganda, B., Mwabu, G. M., Chatora, R. and Mwase, T. (2005). Determinants of health insurance ownership among South African women. BMC Health Services Research, 5(1), pp.17.

Matsa, W. (2011). Who is dependent, third or first world, women or men? Salient features of dependency and interdependency. Journal of Sustainable Development in Africa, 13(6), pp. 202-215

National Health Insurance Authority (NHIA). (2011). Annual Report 2011. Accra-Ghana: National Health Insurance Authority.

Nguyen, H. T., Rajkotia, Y. and Wang, H. (2011). The financial protection effect of Ghana National Health Insurance Scheme: evidence from a study in two rural districts. International Journal for Equity in Health, 10, pp.4 
Nyonator, F. and Kutzin, J. (1999). Health for some? The effects of user fees in the Volta Region of Ghana. Health Policy and Planning, 14(4), pp. 329-341.

Oxfam International. (2011). Achieving a shared goal: Free universal health care in Ghana. United Kingdom: Oxfam International. Retrieved from http://www.oxfam.org/ sites/www.oxfam.org/files/rr-achieving-shared-goal-healthcare-ghana-ogo311-en. pdf

Oxfam International. (2013). Universal health coverage: why health insurance schemes are leaving the poor behind (OXFAM BRIEFING PAPER No. 176). United Kingdom: Oxfam International. Retrieved from http://www.oxfam.org/sites/www.oxfam. org/files/bp176-universal-health-coverage-091013-en_.pdf

Richardson, E., Roberts, B., Sava, V., Menon, R. and McKee, M. (2012). Health insurance coverage and health care access in Moldova. Health Policy and Planning, 27(3), pp. 204-212.

Sen, A. (1999). Development as freedom. New York: Anchor Books.

Wagstaff, A. (2010). Social health insurance reexamined. Health Economics, 19(5), pp. 503517.

World Health Organization. (2005). Sustainable health financing, universal coverage and social health insurance (World Health Assembly Resolution WHA58.33). Geneva: World Health Organization. Retrieved from http://healthcare.procon.org/ sourcefiles/world-health-assembly-resolution-58.33.pdf

World Health Organization. (2013). The world health report 2013: research for universal health coverage. Geneva: World Health Organization. Retrieved from http://apps. who.int/iris/bitstream/10665/85761/2/9789240690837_eng.pdf?ua=1 